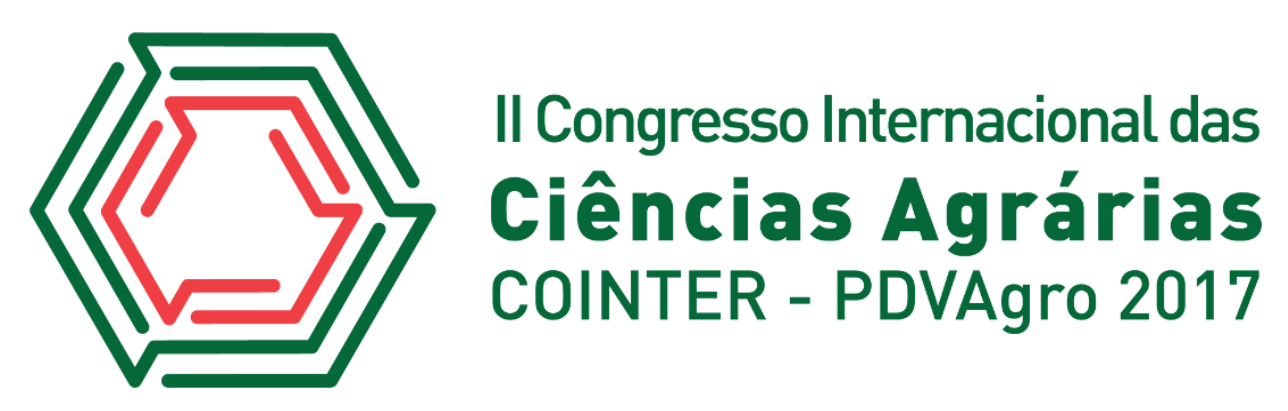

\title{
AULAS DE MONITORIA COMO ALTERNATIVA DE ELEVAR O NÍVEL DE APRENDIZADO PARA ESTUDANTES DA GRADUAÇÃO
}

\author{
Apresentação: Relato de Experiência \\ Danrlei Varela Ribeiro ${ }^{1}$; José Flávio Cardoso Zuza ${ }^{1}$; Edvania Pereira de Oliveira ${ }^{2}$; Bruno \\ Ferreira de Matos ${ }^{3}$; Thiago Jardelino Dias ${ }^{4}$
}

\section{Introdução}

As atividades de monitoria têm como objetivo principal contribuir com o desenvolvimento da competência pedagógica e auxiliar os discentes na produção do conhecimento. De fato, existem algumas peculiaridades nas atividades de monitoria das diferentes Instituições de Ensino Superior (IES), visto que estas possuem normas fixadas pelos seus respectivos conselhos de Ensino Pesquisa e Extensão. (SCHNEIDER, 2006).

Muitos estudantes sentem dificuldades em algumas disciplinas, entre estas a disciplina de irrigação e drenagem, por isso ela é bem requisitada, havendo uma grande procura por monitores, que possam contribuir para um melhor rendimento acadêmico. Diante do exposto trabalho temos como objetivo disseminar à importância das atividades de monitorias para aumentar o aprendizado de estudantes enfocando um aprofundamento teórico de conteúdos ministrados, assim como aumentar o índice de aprovações desta disciplina.

\section{Relato de Experiência}

O desenvolvimento das aulas de monitoria da disciplina de irrigação e drenagem foram realizadas no bloco de aulas Alcydes Marcelino, localizado no Centro de Ciências Humanas Sociais e Agrárias, da Universidade Federal da Paraíba, Campus III - Bananeiras, sendo ministradas semanalmente em horários que foram definidos, entre os alunos e o monitor, na qual foi disponibilizado 8 horas semanais para tirar dúvidas e possíveis sugestões dos alunos matriculados.

\footnotetext{
${ }^{1}$ Licenciatura em Ciências Agrarias, UFPB, danrleivarela@hotmail.com

${ }^{1}$ Licenciatura em Ciências Agrarias, UFPB, jose_flaviocardoso@hotmail.com

${ }^{2}$ Licenciatura em Ciências Agrarias, UFPB, e.edvaniapereira@hotmail.com

${ }^{3}$ Agrônomo, UFPB, ferreira_mattos@yahoo.com.br

${ }^{4}$ Professor do Departamento de Agricultura, UFPB, thiagojardelinodias@gmail.com
} 
Diante disso foram traçadas as seguintes metas para serem alcançadas durante $\mathrm{o}$ semestre letivo, tendo em vista aumentar a elevação do nível de conhecimento dos discentes a partir dos seguintes procedimentos:

1- Dialogo interativo sobre conceitos básicos de irrigação e drenagem a partir das teorias explicadas em sala de aula;

2- Realização de experimentos, possibilitando a utilização de métodos práticos de irrigação para diferentes culturas;

3- Assimilação em sala de aula sobre formulação e resolução de questões problema em sistemas de irrigação;
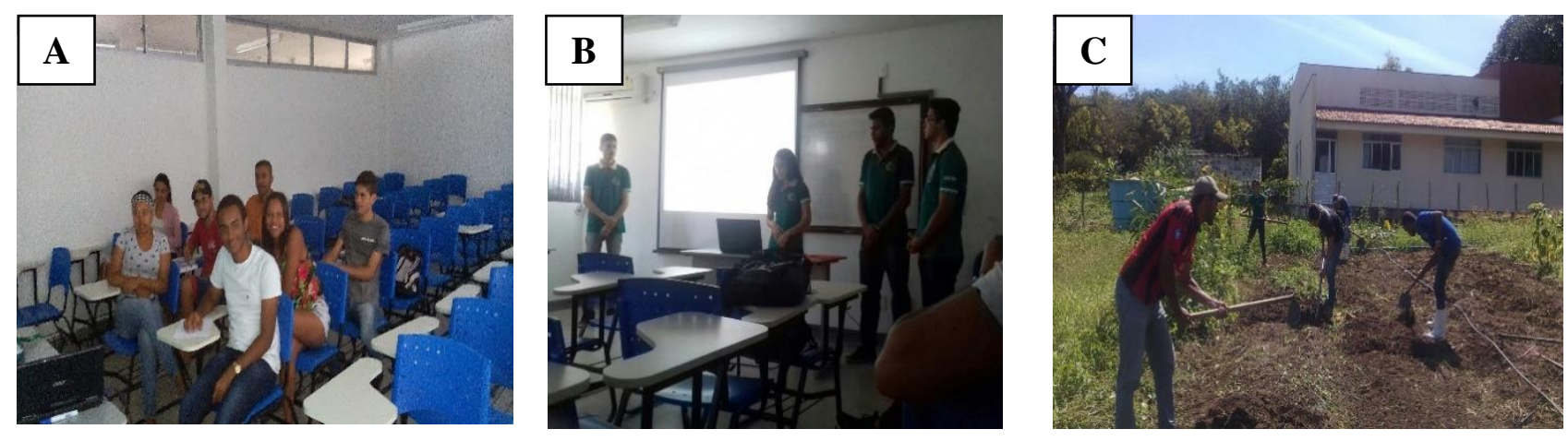

Figura 1.: Aula expositiva sobre ciclo hidrológico (A); Apresentação dos seminários (B);

Montagem dos experimentos (C).

\section{Considerações}

O desenvolvimento da monitoria é um processo que nos auxilia uma grande relação ensinoaprendizagem e que exige por parte do monitor o domínio da disciplina, transparência, e didática do conteúdo permitindo aprofundar-se teoricamente sobre os temas abordados, disseminando os seus conhecimentos para os estudantes. Portanto, a pratica da monitoria auxilia na relação professoaluno, contemplando ao monitor o desenvolvimento da docência e formação didática, contribuindo para sua formação ética e profissional.

\section{Referências}

CARVALHO,D.G.; FABROP.N. A importância das monitorias para a formação do acadêmico do curso de matemática licenciatura In: XIII CIAEM-IACME, Recife,Brasil, 2011.

Disponívelemhttp://www.cimm.ucr.ac.cr/ocs/files/conferences/1/schedConfs/1/papers/1665/supp/16 65-4291-2-SP.pdf 